\title{
A REVIEW OF ONCOLOGY CLINICAL INFORMATION SYSTEMS- WHAT ARE THE CRITICAL SUCCESS FACTORS AND REASONS FOR SYSTEM FAILURE?
}

\author{
Azadeh Yazdanian', Haleh Ayatollahi², Azin Nahvijou ${ }^{3}$ \\ ${ }_{1}$ PhD Student of Health Information Management, School of Health Management and Information Sciences, Iran University of Medical \\ Sciences, Tehran, Iran. \\ ${ }^{2}$ Associate Professor in Medical Informatics, Health Management and Economics Research Center, Iran University of Medical Sciences, \\ Tehran, Iran. \\ ${ }^{3}$ Assistant Professor in Health Management, Cancer Research Center of Cancer Institute of Iran, Tehran University of Medical Sciences, \\ Tehran, Iran.
}

ABSTRACT
BACKGROUND
The large amount of information and their maintenance issues are two main issues in cancer care. To resolve them, the use of
health information technology, such as clinical information systems has been suggested. The present study aimed to review various
clinical information systems used in the field of oncology and the critical success factors influencing system implementation.

\section{MATERIALS AND METHODS}

This review study was completed in 2017. In this study, papers related to clinical information systems in the field of oncology were retrieved by using keywords, such as cancer, cancer information system, radiotherapy information system, and chemotherapy information system. The databases and the search engine were Scopus, PubMed, ScienceDirect, Web of knowledge, Ovid Medline, and Google Scholar and the time frame was between 2010 and 2016. Initially, a total of 302 papers were retrieved, and finally 21 related papers were selected.

\section{RESULTS}

The main clinical information systems used in oncology included cancer information systems, cancer electronic medical records, radiotherapy information systems, chemotherapy information systems, and other systems. The critical success factors were mainly related to the appropriate use of technology, user acceptance, system integration, and paying adequate attention to the users' requirements.

\section{CONCLUSION}

The use of clinical information systems in the field of oncology is inevitable, mainly due to the wide range of benefits that these systems have. However, in order to implement these systems successfully, proper choice of technology, user training, application of standards, periodic evaluations, as well as workflow identification are required for effective use of these systems.

\section{KEY WORDS}

Neoplasm; Cancer; Clinical Information System; Radiotherapy; Hospital.

HOW TO CITE THIS ARTICLE: Yazdanian A, Ayatollahi H, Nahvijou A. A review of oncology clinical information systems- what are the critical success factors and reasons for system failure? J. Evolution Med. Dent. Sci. 2018;7(47):5118-5127, DOI: $10.14260 /$ jemds/2018/1137

\section{BACKGROUND}

It is more than a decade that infectious diseases have been controlled and life expectancy has been improved in the world. On the other hand, the prevalence of noncommunicable and chronic diseases, including cancers has increased and some of them are now the main causes of death.(1) According to the World Health Organization, 2.8 million people lose their lives each year because of cancer. Since early detection, accurate diagnosis, and effective treatment can increase the survival rate of cancer patients, development of various methods for cancer treatment in recent decades has led to increasing life expectancy in most

'Financial or Other Competing Interest': Dr. Ayatollahi reports grants from Iran University of Medical Sciences, outside the submitted work.

Submission 07-10-2018, Peer Review 01-11-2018,

Acceptance 07-11-2018, Published 19-11-2018.

Corresponding Author:

Haleh Ayatollahi,

Associate Professor in Medical Informatics,

Health Management and Economics Research Center,

Iran University of Medical Sciences, Tehran, Iran.

E-mail: ayatollahi.h@iums.ac.ir

DOI: $10.14260 /$ jemds/2018/1137 developed countries.(2) Obviously, progress in the development of various diagnostic and therapeutic methods for treating cancer is related to the progress in data collection and data analysis. In fact, due to the increasing volume of cancer data, the complexity of health plans, the need for realtime measurement of care outcomes, as well as significant changes in oncology activities from outpatient care to hospitalization, the use of clinical information systems has been suggested to increase access, organize and manage cancer related data. $(3,4)$

The use of clinical information systems in oncology is one of the most valuable areas for research, since using these systems can help to facilitate clinical activities. $(5,6)$ Moreover, clinical information systems can help to reduce adverse drug reactions and to increase dosing accuracy by providing information on how to make good use of medicines in cancer care.(7) Oncology information systems, $(8-11)$ oncology electronic medical records, $(4,12,13)$ radiotherapy $(14-22,2)$ and chemotherapy information systems $(23,24)$ are among the systems that are used in hospitals for cancer data management. 
According to the literature review, the benefits of using information systems for data management in oncology include increasing access to information, improving the quality of clinical care, decreasing medical errors, reducing clinical documentation time, reporting outcomes, maintaining confidentiality, improving resource allocation, increasing user satisfaction, and providing rich data for clinical research. $(7,25,26)$ However, these benefits can be hindered due to the lack of physicians' support, user resistance, lack of necessary training, and lack of user-centered design approach during the development of these systems. $(7,5)$

Although design and implementation of clinical information systems in oncology have been investigated in different studies, the number of studies related to the application and the critical success factors influencing system implementation is limited. In 2011, the use of electronic medical systems in cancer was reviewed; however, a limited number of studies were selected, and researchers emphasized on the supporting aspects of information systems in cancer-related clinical activities and assessments. The aim of the present study was to review different studies regarding the application of various clinical information systems in oncology and the critical success factors influencing system implementation.

\section{MATERIALS AND METHODS}

This was a review study which was completed in 2017. The main databases and search engines used to search data were Scopus, PubMed, Science Direct, Web of knowledge, Ovid Medline and Google Scholar. Since studies related to oncology information systems were predominantly found in these databases, these databases were selected. The key terms included cancer, health information technology, electronic medical records, oncology information system, radiotherapy information system, chemotherapy information system, and hospital that were combined using Bolean operators (AND/OR) to find related articles.

The time frame for seeking papers was between 2010 and 2016, and all relevant full text papers which were in English were selected. The non-English articles, letters to the editor, and books were excluded from the study. Initially, 302 papers were obtained, and 17 duplicated ones were removed. Lack of access to the abstract and the full text was another reason for removing 21 papers. The remaining papers $(n=264)$ were evaluated. After reviewing the abstracts, 243 papers were removed due to abstract poor consistency with the aim of this research. The remaining papers $(n=21)$ were used for further investigation (Figure 1) and were evaluated in terms of objectives, methods and results.

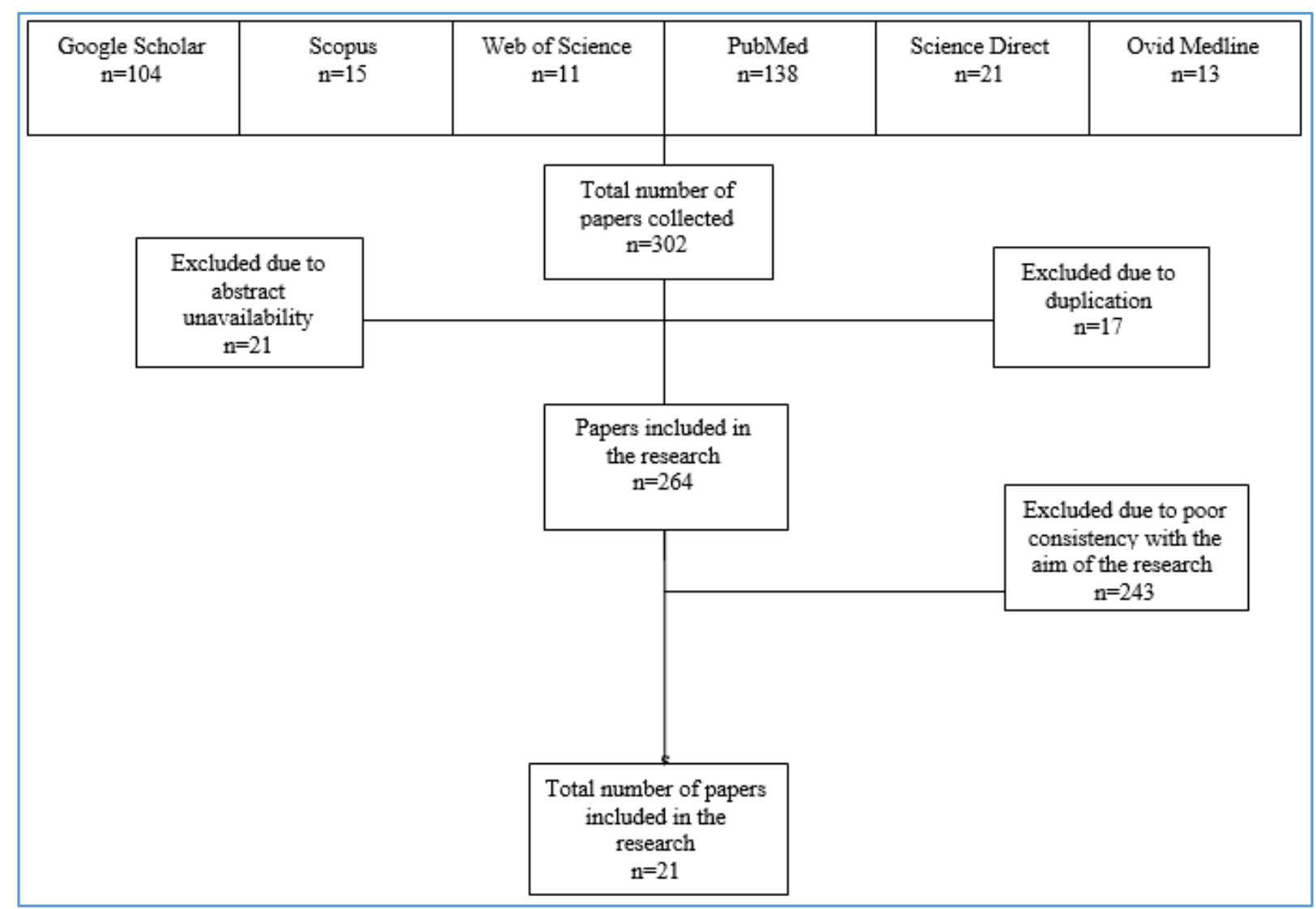

Figure 1. The Process of selecting papers for research

\section{RESULTS}

As previously mentioned, 21 papers were found in this study. The findings indicated that most papers were published in 2012 (Figure 2). These studies were conducted in the following countries: USA (six studies), Australia (three studies), Japan (two studies), Canada (two studies), Germany (two studies), Spain (one study), Netherlands (one study), Italy (one study), Portugal (one study), UK (one study), and Sweden (one study) (Table 1). According to the findings, clinical information systems used in oncology could be divided into five main categories: oncology information system, oncology electronic medical records, radiotherapy information systems, chemotherapy information systems, and others. 


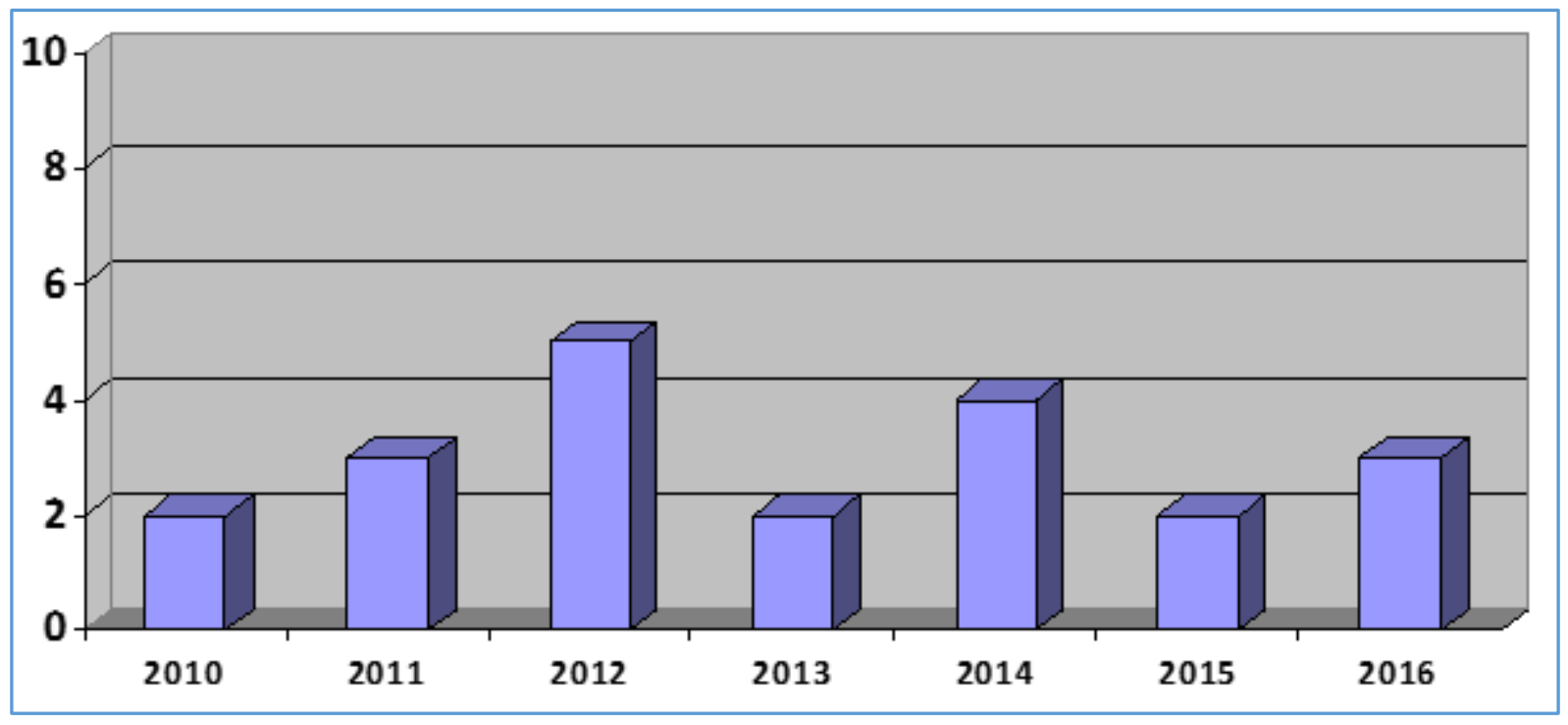

Figure 2. Number of papers published between 2010 and 2016

\begin{tabular}{|c|c|c|c|c|c|}
\hline $\begin{array}{l}\text { Sl. } \\
\text { No. }\end{array}$ & $\begin{array}{c}\text { Author, } \\
\text { Year }\end{array}$ & Country & Objective & Methods & Results \\
\hline 1 & $\begin{array}{c}\text { Sicotte et } \\
\text { al, } \\
2016(13)\end{array}$ & Canada & $\begin{array}{l}\text { To analyse the intermediate and } \\
\text { longer-term changes in patients' } \\
\text { waiting times following the } \\
\text { implementation of a care pathway- } \\
\text { based electronic medical records } \\
\text { (EMR) dedicated to the ambulatory } \\
\text { treatment in both medical and } \\
\text { radiation oncology }\end{array}$ & $\begin{array}{l}\text { Pre and post } \\
\text { evaluation } \\
\text { study }\end{array}$ & $\begin{array}{l}\text { A large majority of the waiting-time indicators } \\
\text { decreased over time, with decreases ranging } \\
\text { from } 2 \text { to } 28 \text { days. However, an important time } \\
\text { lag was necessary to see an improvement, } \\
\text { to the extent that better access was only } \\
\text { observed in the final months of the post period. }\end{array}$ \\
\hline 2 & $\begin{array}{l}\text { Yang, } \\
2016^{(2)}\end{array}$ & Sweden & $\begin{array}{l}\text { To develop a mock-up of user } \\
\text { interfaces for envisaging } \\
\text { radiotherapy workflows }\end{array}$ & $\begin{array}{c}\text { Software } \\
\text { development }\end{array}$ & $\begin{array}{l}\text { The feedback highlighted how the healthcare } \\
\text { personnel were willing to change their current } \\
\text { work methods. The participated healthcare } \\
\text { personnel felt that suggestion of using } \\
\text { electronic patient protocols instead of paper } \\
\text { forms was a good idea to support their } \\
\text { workflows. }\end{array}$ \\
\hline 3 & $\begin{array}{c}\text { Pan et al, } \\
2016(22)\end{array}$ & USA & $\begin{array}{c}\text { To implement a web-based } \\
\text { electronic data capture system for } \\
\text { routine clinical care, and to describe } \\
\text { the experience piloting this system } \\
\text { for breast cancer patients receiving } \\
\text { radiation therapy }\end{array}$ & $\begin{array}{c}\text { Software } \\
\text { development }\end{array}$ & $\begin{array}{l}\text { The EDC system has been used by } 25 \text { providers } \\
\text { for } 1,296 \text { patients. In the most recent month, } \\
978 \text { clinical notes were generated. The average } \\
\text { clinician documentation time over a typical } \\
\text { course of radiation was reduced from } 22.4 \\
\text { minutes per patient with dictation to } 7.1 \\
\text { minutes with EDC. }\end{array}$ \\
\hline 4 & $\begin{array}{c}\text { Kerstin et } \\
\text { al, } \\
2015(15)\end{array}$ & Germany & $\begin{array}{l}\text { To characterize current } \\
\text { developments in combining patient } \\
\text { data from all involved systems in } \\
\text { radiotherapy departments and } \\
\text { practices }\end{array}$ & Quantitative & $\begin{array}{l}\text { University hospitals, community hospitals and } \\
\text { private practices are equally equipped } \\
\text { concerning IT infrastructure for clinical use. } \\
\text { However, private practices have a low interest } \\
\text { in research work. All respondents stated the } \\
\text { biggest obstacles about introducing a } \\
\text { documentation system into their unit lie in } \\
\text { funding and support of the central IT } \\
\text { departments. }\end{array}$ \\
\hline \multicolumn{6}{|c|}{ Table 1. Studies related to the application of clinical information systems in oncology } \\
\hline
\end{tabular}

\begin{tabular}{|c|c|l|c|c|c|}
\hline $\begin{array}{c}\text { Sl. } \\
\text { No. }\end{array}$ & $\begin{array}{c}\text { Author, } \\
\text { Year }\end{array}$ & Country & Objective & Methods & Results \\
\hline 5 & $\begin{array}{c}\text { Mukai } \\
\text { et al, } \\
2015(21)\end{array}$ & Japan & $\begin{array}{c}\text { To develop a data archiving system } \\
\text { for radiotherapy }\end{array}$ & $\begin{array}{c}\text { Software } \\
\text { development }\end{array}$ & $\begin{array}{c}\text { The system included patient demographic and } \\
\text { visit information, radiotherapy order and } \\
\text { delivery information, treatment follow-up } \\
\text { information and laboratory test results. }\end{array}$ \\
\hline 6 & $\begin{array}{c}\text { Fasola } \\
\text { et al, }\end{array}$ & Italy & $\begin{array}{c}\text { To discuss the current use of } \\
\text { computerized clinical information }\end{array}$ & Qualitative & $\begin{array}{c}\text { This study represented an opportunity for both } \\
\text { clinicians and researchers in terms of quality of }\end{array}$ \\
\hline
\end{tabular}




\begin{tabular}{|c|c|c|c|c|c|}
\hline & $2014(27)$ & & $\begin{array}{l}\text { and decision systems in oncology } \\
\text { practice }\end{array}$ & & $\begin{array}{c}\text { care improvement, the use of CDSSs, data } \\
\text { mining, and patient-centered care. In order to } \\
\text { empower the implementation of HIT in } \\
\text { oncology practice, a full involvement of medical } \\
\text { oncologists and their commitment are } \\
\text { mandatory. }\end{array}$ \\
\hline 7 & $\begin{array}{c}\text { Evans } \\
\text { et al, } \\
2014^{(10)}\end{array}$ & Canada & $\begin{array}{l}\text { To describe and discuss the } \\
\text { challenges to implement a region- } \\
\text { wide oncology information system } \\
\text { across four independent health care } \\
\text { organizations }\end{array}$ & $\begin{array}{c}\text { Software } \\
\text { development }\end{array}$ & $\begin{array}{l}\text { The need for change must be shared across } \\
\text { centers. It is essential to establish physician } \\
\text { leadership, commitment, and engagement in the } \\
\text { process. Work processes had to be revised to } \\
\text { optimize use of the new system. Training and } \\
\text { resource requirements must be thoroughly } \\
\text { planned, implemented and monitored. }\end{array}$ \\
\hline 8 & $\begin{array}{l}\text { Ando } \\
2014(8)\end{array}$ & Japan & $\begin{array}{l}\text { To design an oncology information } \\
\text { system }\end{array}$ & $\begin{array}{c}\text { Software } \\
\text { development }\end{array}$ & $\begin{array}{l}\text { The oncology information system can be used to } \\
\text { manage patient treatment schedules, treatment } \\
\text { plans, treatment delivery, treatment summaries } \\
\text { and results. This OIS will encompass the } \\
\text { information exchange between radiation } \\
\text { therapy departments and the overall healthcare } \\
\text { enterprise. }\end{array}$ \\
\hline
\end{tabular}

\begin{tabular}{|c|c|c|c|c|c|}
\hline $\begin{array}{l}\text { Sl. } \\
\text { No. }\end{array}$ & $\begin{array}{l}\text { Author, } \\
\text { Year }\end{array}$ & Country & Objective & Methods & Results \\
\hline 9 & $\begin{array}{l}\text { Shake } \\
\text { shaft } \\
2014(19)\end{array}$ & Australia & $\begin{array}{c}\text { To provide guidance for safe work } \\
\text { practices and a suitable level of } \\
\text { quality control without detailed work } \\
\text { instructions }\end{array}$ & Qualitative & $\begin{array}{l}\text { Both the OIS and OPACS have become mission } \\
\text { critical systems in any modern radiation } \\
\text { oncology department. It is important as part of } \\
\text { the commissioning process to ensure that } \\
\text { business continuity planning has been } \\
\text { performed. Two critical steps in the design of a } \\
\text { disaster recovery plan are identifying and } \\
\text { evaluating risks and defining the recovery } \\
\text { strategy in radiotherapy. }\end{array}$ \\
\hline 10 & $\begin{array}{l}\text { Efstathiou } \\
\text { et al, } \\
2013(18)\end{array}$ & USA & $\begin{array}{c}\text { To design the national radiation } \\
\text { oncology registry for collecting } \\
\text { standardized information on cancer } \\
\text { care delivery among patients treated } \\
\text { with radiotherapy. }\end{array}$ & $\begin{array}{c}\text { Software } \\
\text { development }\end{array}$ & $\begin{array}{l}\text { An electronic infrastructure was developed to } \\
\text { provide connectivity across radiation oncology } \\
\text { and hospital information systems. The initial set } \\
\text { of radiation practice metrics included ordering } \\
\text { of staging scans, active surveillance discussion, } \\
\text { dose prescriptions for low/high-risk diseases, } \\
\text { radiation fields for low/high-risk diseases, } \\
\text { image-guided radiation therapy use, androgen } \\
\text { deprivation therapy use, post-brachy therapy } \\
\text { implant computed tomography dosimetry, } \\
\text { collection of toxicity assessments, and } \\
\text { longitudinal patient follow-up. }\end{array}$ \\
\hline 11 & $\begin{array}{l}\text { Urda et al, } \\
2013(9)\end{array}$ & Spain & $\begin{array}{c}\text { To present the experience on the } \\
\text { design and implementation of a user } \\
\text { centered } \\
\text { oncology information system } \\
\text { developed for the medical oncology } \\
\text { department. }\end{array}$ & $\begin{array}{c}\text { Software } \\
\text { development }\end{array}$ & $\begin{array}{l}\text { The developed system is based on a web } \\
\text { application with a modular and layered } \\
\text { architecture accounting for usability, ease of } \\
\text { maintenance and further system development. } \\
\text { A thorough prior analysis of clinical activities } \\
\text { and workflows, the use of the adequate } \\
\text { technology and the availability of data analysis } \\
\text { tools guarantee success in the deployment of } \\
\text { the oncology information system. }\end{array}$ \\
\hline \multicolumn{6}{|c|}{ Table 1. Continued } \\
\hline
\end{tabular}

\begin{tabular}{|c|c|c|c|c|c|}
\hline $\begin{array}{l}\text { Sl. } \\
\text { No. }\end{array}$ & $\begin{array}{l}\text { Author, } \\
\text { Year }\end{array}$ & Country & Objective & Methods & Results \\
\hline 12 & $\begin{array}{c}\text { Oliveira et } \\
\text { al } \\
2012(20)\end{array}$ & Portugal & $\begin{array}{c}\text { To assess expert's opinion about } \\
\text { DICOM-RT and information system } \\
\text { interoperability in the radiotherapy } \\
\text { context }\end{array}$ & Quantitative & $\begin{array}{l}\text { The results showed that the radiotherapy } \\
\text { departments have some equipment and } \\
\text { information systems from different vendors } \\
\text { contributing for heterogeneity of radiotherapy } \\
\text { workflows. The experts had low knowledge } \\
\text { about their own information system } \\
\text { integrations and DICOM-RT. }\end{array}$ \\
\hline 13 & Ries et al, & Germany & To present an EMR based approach & Software & The system log and the results of a user survey \\
\hline
\end{tabular}




\begin{tabular}{|c|c|c|c|c|c|}
\hline & $2012(12)$ & & $\begin{array}{c}\text { to visualize all cancer relevant data in } \\
\text { a so-called cancer diary at a single } \\
\text { glance }\end{array}$ & development & $\begin{array}{l}\text { demonstrated increasing use and good usability } \\
\text { of the cancer diary compared to traditional } \\
\text { searches for relevant information in the entire } \\
\text { patient EMR. In fact, a cancer diary aggregating } \\
\text { data of diagnostic staging, tumor conference } \\
\text { decisions and therapeutic actions may be a } \\
\text { valuable EMR extension for hospitals focusing } \\
\text { on cancer care. }\end{array}$ \\
\hline 14 & $\begin{array}{l}\text { Santos } \\
\text { et al, } \\
2012(14)\end{array}$ & USA & $\begin{array}{l}\text { To map the level of clinical practice } \\
\text { compatibility with a radiation } \\
\text { oncology information system (ROIS) } \\
\text { through a workflow and clinical } \\
\text { process-based method }\end{array}$ & $\begin{array}{l}\text { Mixed method } \\
\text { (Qualitative and } \\
\text { Quantitative) }\end{array}$ & $\begin{array}{l}\text { Practice-specific processes and infrastructure } \\
\text { maps were generated. The developed survey } \\
\text { was applied, and results indicated a range of } \\
\text { ROIS compatibility with clinical workflow and } \\
\text { infrastructure. The survey results provided } \\
\text { specific guidance to improve both ROIS } \\
\text { performance and clinic-specific processes and } \\
\text { infrastructure. }\end{array}$ \\
\hline 15 & $\begin{array}{c}\text { Santanam } \\
\text { et al, } \\
2012(16)\end{array}$ & USA & $\begin{array}{c}\text { To identify deficiencies with } \\
\text { simulation and treatment planning } \\
\text { orders and to develop corrective } \\
\text { measures to improve safety and } \\
\text { quality }\end{array}$ & $\begin{array}{c}\text { Software } \\
\text { development }\end{array}$ & $\begin{array}{l}\text { An interdisciplinary group evaluated and } \\
\text { decided to replace the Microsoft word-based } \\
\text { form with a web-based order system. The } \\
\text { average time to complete the SIMulation and } \\
\text { treatment PLanning Electronic (SIMPLE) form } \\
\text { was } 3 \text { minutes, as compared with } 7 \text { minutes for } \\
\text { the word-based form. }\end{array}$ \\
\hline \multicolumn{6}{|c|}{ Table 1. Continued } \\
\hline
\end{tabular}

\begin{tabular}{|c|c|c|c|c|c|}
\hline $\begin{array}{l}\text { Sl. } \\
\text { No. }\end{array}$ & $\begin{array}{c}\text { Author, } \\
\text { Year }\end{array}$ & Country & Objective & Methods & Results \\
\hline 16 & $\begin{array}{l}\text { Yang } \\
\text { et al, } \\
2012(17)\end{array}$ & USA & $\begin{array}{l}\text { To improve quality and efficiency of } \\
\text { patient chart checking in radiation } \\
\text { oncology departments }\end{array}$ & $\begin{array}{c}\text { Software } \\
\text { development }\end{array}$ & $\begin{array}{c}\text { The software was successfully implemented in } \\
\text { the clinical environment and has demonstrated } \\
\text { the feasibility of automation of this common } \\
\text { task with modern clinical tools. The software } \\
\text { integrates multiple disconnected systems and } \\
\text { successfully supports analysis of data in diverse } \\
\text { formats. }\end{array}$ \\
\hline 17 & $\begin{array}{l}\text { Pirnejad } \\
\text { et al, } \\
2011(23)\end{array}$ & Netherlands & $\begin{array}{l}\text { To implement two different } \\
\text { information systems with respect to } \\
\text { their ability to afford clinicians' } \\
\text { needs in the chemotherapy } \\
\text { medication process }\end{array}$ & $\begin{array}{c}\text { Software } \\
\text { development }\end{array}$ & \begin{tabular}{|} 
The systems were evaluated from users' \\
perspectives to find the sources of clinicians' \\
preference. Kuren was the system of preference \\
for haematologists/oncologists because it could \\
support the complex chemotherapy process \\
and managed its user requirements better. The \\
advantages of Kuren were built into the system \\
through a user requirement driven and \\
process-oriented design.
\end{tabular} \\
\hline 18 & $\begin{array}{l}\text { Hains } \\
\text { et al, } \\
2011(5)\end{array}$ & Australia & $\begin{array}{l}\text { To examine the literature on ICT } \\
\text { systems in non-radiation oncology } \\
\text { cancer care, particularly medical } \\
\text { oncology }\end{array}$ & Qualitative & $\begin{array}{l}\text { There are many claims throughout the } \\
\text { literature about the benefits of ICT in } \\
\text { supporting medical oncology practice. Studies } \\
\text { were limited to one system and modest } \\
\text { qualitative data sets were assembled in most } \\
\text { studies. Particular areas of focus suggested by } \\
\text { this review included how, to what extent and in } \\
\text { what ways have ICT systems: changed clinical } \\
\text { practices and health care delivery; improved } \\
\text { processes; supported best practice; reduced } \\
\text { errors or adverse events; enabled better } \\
\text { decision-making, teamwork and } \\
\text { communication within provider groups and } \\
\text { between providers and patients. }\end{array}$ \\
\hline \multicolumn{6}{|c|}{ Table 1. Continued } \\
\hline
\end{tabular}




\begin{tabular}{|c|c|c|c|c|c|}
\hline $\begin{array}{l}\text { Sl. } \\
\text { No. }\end{array}$ & $\begin{array}{c}\text { Author, } \\
\text { Year }\end{array}$ & Country & Objective & Methods & Results \\
\hline 19 & $\begin{array}{c}\text { Levy } \\
\text { et al, } \\
2011^{(24)}\end{array}$ & USA & \begin{tabular}{|} 
To describe the specialized \\
configuration of clinical informatics \\
systems for electronic \\
chemotherapy medication \\
administration
\end{tabular} & $\begin{array}{c}\text { Software } \\
\text { development }\end{array}$ & $\begin{array}{c}\text { The configured systems facilitated } \\
\text { compliance with the ASCO/ONS guidelines } \\
\text { and improved the consistency of } \\
\text { documentation and multidisciplinary } \\
\text { team communication. However, several } \\
\text { limitations remained with regard to } \\
\text { recording the day of treatment and dose } \\
\text { number. }\end{array}$ \\
\hline 20 & $\begin{array}{l}\text { Yu et al, } \\
2010(11)\end{array}$ & Australia & $\begin{array}{c}\text { To compare the implementation and } \\
\text { use of the same oncology } \\
\text { information system (OIS) in two } \\
\text { public hospitals and account for any } \\
\text { differences in the use of the system }\end{array}$ & Qualitative & $\begin{array}{l}\text { Hospital A used the OIS in all aspects of } \\
\text { clinical documentation. With no vision of } \\
\text { developing a paperless information system, } \\
\text { Hospital B used the OIS only for booking } \\
\text { and patient tracking. Reasons for the } \\
\text { different use of the OIS: Staff } \\
\text { demographics, leadership, the project } \\
\text { managers contribution, clinicians' attitudes } \\
\text { towards the OIS, etc. }\end{array}$ \\
\hline 21 & $\begin{array}{l}\text { Poulter } \\
\text { et al, } \\
2010^{(4)}\end{array}$ & England & $\begin{array}{l}\text { To describe a reference model for } \\
\text { the use of electronic patient record } \\
\text { (EPR) systems in oncology }\end{array}$ & $\begin{array}{c}\text { Software } \\
\text { development }\end{array}$ & $\begin{array}{l}\text { An electronic document and records } \\
\text { management (EDRM) system was } \\
\text { monitored in the course of its deployment } \\
\text { at a leading oncology centre in the UK. The } \\
\text { initial analysis indicates a good case for } \\
\text { EDRM, with just under half (43\%) of } \\
\text { respondents reporting that they think they } \\
\text { will spend less time waiting or searching } \\
\text { for patient information when patients' } \\
\text { records are fully electronic and half (49\%) } \\
\text { expecting that clinical information will be } \\
\text { more up-to-date. }\end{array}$ \\
\hline \multicolumn{6}{|c|}{ Table 1. Continued } \\
\hline
\end{tabular}

\section{Oncology Information System (OIS)}

The findings revealed that between 2010 and 2016, three studies were related to the design and implementation of oncology information systems and were published in Spain,(9) Canada(10) and Japan.(8) Another study was completed in Australia and the experiences of physicians and therapists regarding an oncology information system were evaluated in this study.(11) In the first three studies, a new system was developed,(8-10) while in the fourth study, a qualitative study was conducted.(11) Each paper is discussed in the following section.

The oncology information system that was created at the University of Málaga (Spain) was a web-based application with a layered architecture that had five modules of patient management, outpatient treatment unit, clinical research, genetic counseling, and statistical analysis. Database management and user access control modules were also considered to register errors and to manage users' roles and activities. Initially, 79\% of users believed that the system had increased their daily workload; however, after one year, only $43 \%$ of them insisted on their point of view. The availability of data analysis tools, integration with workflows, the possibility of transferring data between different systems, and the user-friendly design were among the critical success factors of the system.(9)

In another study in Canada, a geographic oncology information system was implemented in four healthcare organizations. Since these organizations had their own culture and work processes, they faced with many challenges in the process of adopting a standard approach. The findings of this study demonstrated that commitment and active participation of all managers are necessary to achieve desired outcomes. Besides, business processes should be reviewed for optimizing the use of oncology information system, selecting appropriate technologies, and defining new workflows. Furthermore, periodic assessments are required to ensure the fulfilment of project objectives.(10)

In 2014, an oncology information system was designed at the National Institute of Radiation in Japan. The system included a physician order entry system, care planning, outcomes registration, as well as data storage. Scheduling the treatment, developing health plans, and providing a brief report of the treatment and its outcomes in oncology and radiotherapy department were other features of this system. In addition, the system had a clinical database for summarizing and analysing outcomes. In this study, the need for using standards, such as DICOM-RT in radiotherapy, IHE data integration for describing workflows, and HL7 for electronic data transmission between an oncology information system and other hospital information systems has been highlighted.(8)

In another study, the experiences of physicians and therapists in the development and use of an oncology information system were evaluated in two hospitals, in Australia. The purpose of using an oncology information system in hospital A was to implement a paperless filing system, while the main reason for using the system in hospital B was the lack of data integration. The advantages of oncology information system in hospital A included patient appointment scheduling, recording medical history, demonstrating test results, diagnosing and grading the cancer, prescribing radiation therapy, and so forth. However, in hospital B, only patient appointment scheduling was used. Finally, the results indicated that the critical success factors 
of the system in hospital A were user acceptance, managerial commitment, clinical leadership, efficient project management, user involvement and training.(11)

\section{Oncology Electronic Medical Records (OEMR)}

From three studies that were conducted regarding the development of oncology electronic medical records, one study was about establishing electronic medical records and cancer-related data collection. The findings indicated that the users were willing to use cancer care electronic medical records. Training the users and designing the system based on the users' requirements were mentioned as factors affecting the deployment of the system.(12)

Another study evaluated mid and long-term changes in patients' waiting time following the implementation of an electronic medical record system in outpatient oncology and radiotherapy centers in Canada. Defining 175 standard routes of care in radiotherapy and 250 routes of care in oncology were among the main achievements of this study. These issues were considered in the system design. The findings showed that using the system enhanced the flow of information and reduced the average waiting time for patients. ${ }^{(13)}$

The evaluation of oncology electronic medical records was the aim of another study conducted in the UK. In this study, a reference model, CICERO, was introduced for the use of an oncology electronic medical records system. The CICERO model (Comprehensive, Integrated, Customized, Electronic Records for Oncology) had the following capabilities: an integrated patient administration system, order communications and results reporting for pathology and radiology, electronic scheduling, prescribing and drug administration for complex chemotherapy regimens, radiotherapy action sheets, scheduling and pre-treatment workflow, etc. The results showed that the users were happy with the efficacy of the system updating information, improving the quality of care, making informed decisions, and reducing the time of searching for patient data.(4) Regarding the research methods, software development approach was used in the first and the third study, $(4,12)$ while in the second study, the system was evaluated before and after implementation.(13)

\section{Radiotherapy Information Systems}

The findings showed that the use of clinical information systems in radiotherapy department was examined in different studies. Software development, $(22,21,16-18,2)$ was the research methodology in six studies. Other studies used quantitative methods.(15,20) qualitative methods, ${ }^{(19)}$ and mixed methods (qualitative and quantitative).(14) The aims of these studies were creating a national radiation oncology registry,(18) determining the level of compliance of clinical activities with a radiotherapy information system,(14) identifying deficiencies in treatment plans and radiotherapy simulation,(16) developing a patient's electronic chart,(17) and creating a web-based radiotherapy system.(22)

The overall goal of the national radiation oncology registry was improving the quality of cancer treatment through assessing outcomes and providing real-time care. (18) Determining the level of compliance of clinical activities with a radiotherapy information system provided some feedback to enhance radiotherapy oncology information, IT infrastructure, and clinical functions.(14) In another study, an intelligent SIMulation and treatment Planning Electronic (SIMPLE) order system was designed. The system provided an opportunity to create and save templates of treatment plans and simulation. After executing SIMPLE plan, the incidence of events in radiotherapy department decreased from $13 \%$ to $6 \%$. In addition, the average time required to complete the electronic forms compared to the wordtemplate forms decreased from seven minutes to three minutes.(16) A patient's Electronic Chart Check (ECCK) was created by Yang et al to collect electronic data and to analyse patient's treatment information. The system was able to provide more time for more important tasks through eliminating simple and repetitive activities.(17) In Pan et al.'s study, a web-based data collection system was developed to improve clinical documentation in radiotherapy. The results indicated that in addition to facilitating the reporting of outcomes, the system reduced the average time of documentation by physicians from 22 to 7 minutes per patient, and $92 \%$ of respondents were satisfied with the system. ${ }^{(22)}$

Other research objectives were creating a filing system for radiotherapy, (21) developing a mock-up of a user interface to predict radiotherapy workflows,(2) determining the progress of information technology in the radiotherapy section,(15) providing guidance to achieve an appropriate level of quality control(19) and evaluation of experts' opinions about the use of DICOM-RT in radiotherapy.(20)

In a research conducted by Mukai et al. a filing system for radiotherapy department was created. In this system, electronic medical records were used as input for collecting radiotherapy data and another system was used for reporting and summarizing radiation therapy. This system was created by using standard technologies.(21) In 2016, Yang developed a mock-up for predicting radiotherapy workflows. In this study, electronic health plans were designed. The results of the interviews showed that the radiotherapy staff were happy to change their existing workflows. Besides, they regarded using electronic protocols as an appropriate method for supporting their workflows.(2)

Regarding the advancements of information technology in radiotherapy, the findings showed that economic constraints and insufficient support of information technology in the hospitals were the most important barriers towards creating a radiotherapy documentation system.(15)

In 2014, Shakeshaft et al. provided recommendations for achieving the appropriate level of quality in radiotherapy. Since, it is crucial to identify errors and to provide an appropriate approach in a disaster recovery plan, testing failover between servers, testing treatment plan delivery during a network or a server failure, and taking backup and restoring data should receive more attention.(19)

In relation to the application of DICOM-RT (A standard method for data transfer in radiotherapy workflows which describes six major areas, the structure of radiotherapy, radiation treatment plan, radiotherapy dose, radiotherapy image, treatment records, and summary of treatment records) and interoperable systems, the analysis of the experts' opinions showed that there was a lack of compatibility between equipment and information systems with radiotherapy workflows. In addition, there was limited knowledge about the use of DICOM-RT, and finally, it was 
recommended to use this standard to enhance interactions between information systems in the radiotherapy department.(20)

\section{Chemotherapy Information System}

According to the results, only two studies were related to the design of chemotherapy information systems. In both studies, a new system was designed development.(23,24) One study was related to the design of a new information system. This system; namely, Kuren, was designed to plan chemotherapy procedures based on the medical protocols, to provide chemotherapy doses based on the patient's biometric indices, and to support clinical decisions. One year after the system implementation, the findings demonstrated that Kuren was able to support complex processes of chemotherapy and work procedures. The success factors included user-centered design, reducing the workload of physicians, ease of use, flexibility, and supporting multi-disciplinary processes.(23)

In another study, a new system was developed to manage chemotherapy medications. In fact, researchers developed a system by integrating patient administration system, physician order entry system, pharmacy information system, nursing documentation system, and electronic health records. Finally, a form was developed in electronic health records to collect chemotherapy-related data, evaluate symptoms before treatment, and instruct chemotherapy procedures. In fact, this form provided a history of chemotherapy medications in various medical centers. The findings suggested that this system could be used to enhance the readability of documents, improve communication between clinicians, and increase simultaneous access of multiple users to data.(24)

\section{Other Studies}

The application of various health information technology and electronic systems in the field of oncology were discussed in other studies.(27,5) A review study conducted by Fasola et al. highlighted the role of clinical decision support systems and computerized physician order entries in managing standardized cancer treatment regimens, setting appointments, sharing patient data, and monitoring toxicities. The main obstacles related to the application of health information technology by oncologists included the complex nature of the systems, lack of adequate training, spending considerable time and money to run the systems, lack of interoperability, and concerns about the privacy and security.(27)

In another review study, the use of information and communication technology in cancer care (Regardless of radiation) was explored. The findings showed that the use of the technology may have several advantages and disadvantages; however, there was limited evidence regarding the impact of information and communication technology in oncology.(5)

\section{DISCUSSION}

In order to improve quality of cancer care and clinical research, the use of information and communication technology seems to be inevitable to be able to manage the increasing volume of health data. Therefore, the use of clinical information systems in the field of oncology has been suggested to manage related data. The main advantages of using these systems include improving the quality of care, reducing medical errors, decreasing clinical documentation time, providing rich data for clinical research, and controlling health costs. $(27,28)$

In the current study, a number of papers related to the use of clinical information systems in the field of oncology and published between 2010 and 2016 were reviewed. Most of these studies were conducted in USA (Six Studies) and other developed countries such as Australia, Germany, and Canada. Therefore, considering the importance of these systems in improving the quality of care for cancer patients and facilitating clinical activities, the research in this area seems to be limited. In fact, given the complexity of care and workflows in the field of oncology, numerous studies can be conducted to explore the application of clinical information systems in oncology. Besides, since most of these studies were conducted in the developed countries, similar studies in developing countries seem to be necessary to be able to compare similarities and differences.

The findings indicated that a significant number of studies aimed at designing and implementing radiotherapy information systems.(2,14-22) Since most of the radiotherapy information systems contain scattered data from other information systems, it is essential to pay more attention to the standardization and the clinicians' workflows. The application of DICOM-RT standard has been suggested in various studies. DICOM-RT consists of six main objectives which are radiotherapy structure, radiation treatment planning, radiation dose, radiation image, radiation treatment documents, and a summary of radiotherapy documents. This standard offers a standard method for data transfer in radiotherapy department.(15,19) Therefore, such a standard approach can be adopted to manage radiotherapy departments more efficiently.

According to the results, despite the complicated procedure of chemotherapy mainly in calculating medication doses, only two studies were relevant to the use of clinical information systems in the field of chemotherapy.(23,24) It seems that, conducting future studies in this area would be beneficial, as these systems can be useful for calculating chemotherapy medication doses, supporting clinical decisions and chemotherapy protocols, and alerting the time of injections.

The study findings showed that although numerous clinical information systems have been developed in the field of oncology, a limited number of these systems were evaluated and there is little evidence regarding the impact of these systems on cancer care. In fact, similar to other areas, these systems need to be evaluated based on certain criteria to maximize the benefits obtained from them. $(5,11)$

Overall, this review study showed that clinical information systems in the field of oncology can help to improve the readability of documents, to enhance the flow of information, to reduce the searching time, to provide complicated treatments plans, to eliminate errors in prescribing, to assess clinical outcomes, to provide evidencebased activities, to reduce waiting time, and to control health costs. Obviously, these benefits can be achieved following successful system implementation. According to the findings, the most important success factors of these systems were as follows: clinical leadership, paying attention to the clinical and organizational processes, workflow re-engineering, application of electronic protocols, system integration, the 
use of data analytical tools, the use of systematic quality assurance programs, user-friendly interface design, user satisfaction, user training, and application of standards. $(16-22,8-10,2)$

On the other hand, the following issues can be mentioned as the causes of failure of using clinical information systems in the field of oncology: the lack of efficient leadership, the lack user involvement, the lack of change management strategy, the negative impact of the system on the users' workload, the use of unique solutions for different centers, the lack of periodic evaluation, little knowledge about the integration of information systems, budget constraints, and insufficient support of information technology department. In addition, the complexity of the system, considerable cost and time for implementation, the need for standardization, and concerns over patient safety, security, confidentiality, and quality of care were the main obstacles in front of using these systems. $(20,10,9)$ It seems that before designing and applying such systems, a thorough understanding of care processes and workflows is necessary to avoid any failure in the future. This approach can help to identify users' requirements before designing systems and increase the possibility of successful system implementation.

\section{CONCLUSION}

The deployment of clinical information systems in the field of oncology seems to be useful to perform daily activities. These systems help to improve quality of care, medical documentation, resource allocation, and cost effectiveness of health care services. To achieve these benefits, a usercentered and participatory design method should be applied. In fact, the variety of workflows and information needs in different departments are the main reasons for designing different systems. To ensure the systems are successfully implemented, evaluation studies are inevitable. The evaluation helps to identify critical success factors and the reasons for system failure which are a basis for future system development. Future research may pay more attention to the evaluation of the systems' functions as well as the impact of the systems on patient care and daily activities.

\section{ACKNOWLEDGMENTS}

This study was funded and supported by Iran University of Medical Sciences, Tehran, Iran (IUMS/SHMIS_94/36).

\section{REFERENCES}

[1] Martin DB, Kaemingk D, Frieze D, et al. Safe implementation of computerized provider order entry for adult oncology. Appl Clin Inform 2015;6(4):63849.

[2] Ohlin YYY. A case study to investigate the feasibility of supporting radiotherapy workflows through the use of mobile devices. Sweden 2016.

[3] Kessel KA, Bohn C, Engelmann U, et al. Five-year experience with setup and implementation of an integrated database system for clinical documentation and research. Comput Methods Programs Biomed 2014;114(2):206-17.

[4] Polter T, Gannon B, Bath PA. An analysis of electronic document management in oncology care. Health Informatics J 2012;18(2):135-46.
[5] Heins I, Marks D, Ward RL, et al. Medical electronic systems in oncology: a review of the literature. Australian Institute of Health Innovation, Faculty of Medicine, University of New South Wales, 2011.

[6] Wager K, Lee F, Glaser J. Health care information systems: a practical aproach for health care management. 3rd edn. Jossey-Bass 2013.

[7] Bjugn R, Casati B, Haugland HK. Structured electronic health records. Tidsskr Nor Laegeforen 2014;134(4):431-3.

[8] Ando Y. Oncology Informatin System. Carbon-Ion radiotherapy: principles, practices and treatment planning, Japan. 2014: p. 113-7.

[9] Urda D, Ribelles N, Subirats JL, et al. Addressing critical issues in the development of an Oncology Information System. Int J Med Inform. 2013;82(5):398-407.

[10] Evans WK, Ashbury FD, Hogue GL, et al. Implementing a regional oncology information system: approach and lessons learned. J Curr Oncol 2014;21(5):224-33.

[11] Yu P, Gandhidasan S, Miller AA. Different usage of the same oncology information system in two hospitals in Sydney-lessons go beyond the initial introduction. Int J of Med Inform 2010;79(6):422-9.

[12] Ries M, Golcher H, Prokosch HU, et al. An EMR based cancer diary - utilisation and initial usability evaluation of a new cancer data visualization tool. Stud Health Technol Inform 2012;180:656-60.

[13] Scicotte C, Lapointe J, Clavel S, et al. Benefits of improving processes in cancer care with a care pathway-based electronic medical record. Pract Radiat Oncol 2016;6(1):26-33.

[14] De Los Santos FLE, Herman MG. Radiation oncology information systems and clinical practice compatibility: workflow evaluation and comprehensive assessment. Pract Radiation Oncol 2012;2(4):e155-e64.

[15] Kessel KA, Combs SE. Data management, documentation and analysis systems in radiation oncology: a multi-institutional survey. Radiat Oncol J 2015;10:230.

[16] Santanam L, Brame RS, Lindsey A, et al. Eliminating inconsistencies in simulation and treatment planning orders in radiation therapy. Int J Radiat Oncol Biol Phys 2013;85(2):484-91.

[17] Yang D, Wu Y, Brame RS, et al. Technical note: electronic chart checks in a paperless radiation therapy clinic. Med Phys 2012;39(8):4726-32.

[18] Efstathiou JA, Nassif D, McNutt TR, et al. Practicebased evidence to evidence-based practice: building the National Radiation Oncology Registry. J Oncol Pract 2013;9(3):e90-e5.

[19] Shakeshaft J, Perez M, Tremethick L, et al. ACPSEM ROSG Oncology-PACS and OIS working group recommendations for quality assurance. Australas Phys Eng Sci Med 2014;37(1):3-13.

[20] Oliveira CM, Rodrigues PP. The relevance of DICOM-RT in radiotherapy information systems. HEALTHINF 2012, International Conference on Health Informatics: Porto, Portugal 2012: p. 131-6. 


\section{Jemds.com}

[21] Mukai M, Ando Y, Yokooka Y, et al. Development of clinical database system specialized for heavy particle therapy. Stud Health Technol Inform 2015;216:933.

[22] Pan HY, Shaitelman SF, Perkins GH, et al. Implementing a real-time electronic data capture system to improve clinical documentation in radiation oncology. J Am Coll Radiol 2016;13(4):401-7.

[23] Pirnejad H, Niazkhani Z, Aarts J, et al. What makes an information system more preferable for clinicians? A qualitative comparison of two systems. Me Inform (Lond) 2011: p. 392-6.

[24] Levy MA, Giuse DA, Eck C, et al. Integrated information systems for electronic chemotherapy medication administration. J Oncol Pract 2011;7(4):226-30.

[25] Mishuris RG, Linder JA. Racial differences in cancer screening with electronic health records and electronic preventive care reminders. J Am Med Inform Assoc 2014;21(e2):e264-e9.

\section{Original Research Article}

[26] Prokosch HU, Ries M, Beyer A, et al. IT infrastructure components to support clinical care and translational research projects in a comprehensive cancer center. Stud Health Technol Inform 2011;169:892-6.

[27] Fasola G, Macerelli M, Follador A, et al. Health information technology in oncology practice: a literature review. Cancer Inform J 2014;13:131-9.

[28] Bettencourt-Silva J, De La Iglesia B, Donell S, et al. On creating a patient-centric database from multiple hospital Information Systems. Methods Inf Med 2012;51(3):210-20. 